\title{
Endoscopic transsphenoidal anterior petrosal approach for locally aggressive tumors involving the internal auditory canal, jugular fossa, and cavernous sinus
}

\author{
Masahiro Shin, MD, ${ }^{1}$ Kenji Kondo, MD, ${ }^{2}$ Shunya Hanakita, MD, ${ }^{1}$ Hirotaka Hasegawa, MD, \\ Masanori Yoshino, MD, ${ }^{1}$ Yu Teranishi, MD, ${ }^{1}$ Taichi Kin, MD, ${ }^{1}$ and Nobuhito Saito, MD${ }^{1}$ \\ Departments of ${ }^{1}$ Neurosurgery and ${ }^{2}$ Otolaryngology, the University of Tokyo Hospital, Tokyo, Japan
}

\begin{abstract}
OBJECTIVE Reports about endoscopic endonasal surgery for skull base tumors involving the lateral part of petrous apex remain scarce. The authors present their experience with the endoscopic transsphenoidal anterior petrosal (ETAP) approach through the retrocarotid space for tumors involving the internal auditory canal, jugular fossa, and cavernous sinus.

METHODS The authors performed the ETAP approach in 10 patients with 11 tumors (bilateral in 1 patient) that extensively occupied the lateral part of petrous apex, e.g., the internal auditory canal and jugular fossa. Eight patients presented with diplopia (unilateral abducens nerve palsy), 3 with tinnitus, and 1 with unilateral hearing loss with facial palsy. After wide anterior sphenoidotomy, the sellar floor, clival recess, and carotid prominence were verified. Tumors were approached via an anteromedial petrosectomy through the retrocarotid triangular space, defined by the cavernous and vertical segments of the internal carotid artery (ICA), the clivus, and the petrooccipital fissure. The surgical window was easily enlarged by drilling the petrous bone along the petrooccipital fissure. After exposure of the tumor and ICA, dissection and resection of the tumor were mainly performed under direct visualization with $30^{\circ}$ and $70^{\circ}$ endoscopes.
\end{abstract}

RESULTS Gross-total resection was achieved in 8 patients ( 9 tumors). In a patient with invasive meningioma, the tumor was strongly adherent to the ICA, necessitating partial resection. Postoperatively, all 8 patients who had presented with abducens nerve palsy preoperatively showed improvement within 6 months. In the patient presenting with hearing loss and facial palsy, the facial palsy completely resolved within 3 months, but hearing loss remained. Regarding complications, 3 patients showed mild and transient abducens nerve palsy resolving within 2 weeks, 3 months, and 6 months. Postoperative CSF rhinorrhea requiring surgical repair was observed in 1 patient. No patient exhibited hearing deterioration, facial palsy, or symptoms of lower cranial nerve palsy after surgery.

CONCLUSIONS The ETAP approach can offer a simple, less invasive option for invasive skull base tumors involving petrous regions, including the internal auditory canal, jugular fossa, and cavernous sinus. The ETAP approach can reach more extensive areas in the extradural regions around the petrous bone. The authors' results indicate that the transsphenoidal retrocarotid route is sufficient to approach the petrosal areas in select cases. Further expansion of the surgical field is not always necessary. However, experience with intradural lesions remains limited, and the extent of tumor resection largely depends on tumor characteristics. Application of the ETAP approach should thus be carefully determined in each patient, taking into consideration the size of the retrocarotid window and tumor characteristics.

http://thejns.org/doi/abs/10.3171/2016.1.JNS151979

KEY WORDS endoscopic transsphenoidal surgery; anterior petrosal approach; internal auditory meatus; jugular fossa; cavernous sinus; oncology

$\mathrm{S}$ INCE first presented by Kawase et al. in $1991,{ }^{18}$ the anterior transpetrosal approach has become established as a surgical method offering safe access to skull base lesions in the petroclival area, petrous apex, cavernous sinus, and ventral posterior cranial fossa..$^{5,29,34,40}$
With this approach, the access route is demarcated by the trigeminal nerve, internal auditory canal (IAC), and posterior and medial margins of the internal carotid artery (ICA); several authors have reported good surgical outcomes for unilateral skull base lesions. 
About half a decade later, Jho et al. reported their experience with endoscopic endonasal transsphenoidal surgery for pituitary tumors. ${ }^{15,16}$ Since then, over the past 2 decades, introduction of endoscopic technologies into the neurosurgical field has dramatically changed the role of transsphenoidal surgery. Currently, application of this surgical technique has been expanded to the ventral skull base regions, such as the anterior cranial fossa, ${ }^{19,20}$ parasellar region, ${ }^{4,6,38}$ clival region, ${ }^{10,28,30,35}$ and craniovertebral junction. ${ }^{31,39}$

Despite success in those paramedian territories, skull base tumors in the lateral regions remain a therapeutic challenge. Particularly for the petrous region, there have been numerous anatomical studies using cadaveric specimens or radiographic models..$^{921,25,37}$ However, in terms of clinical cases, most of the pathologies addressed using this method have been cystic inflammatory lesions such as cholesterol granuloma or petrous apicitis. ${ }^{12,22,36,41} \mathrm{Re}$ ports remain quite limited regarding experiences with endoscopic transnasal surgery aimed at radical resection of invasive skull base tumors around the petrous regions, including the IAC, jugular fossa, and cavernous sinus. ${ }^{23,24,32}$

When tumors with aggressive behavior occupy the lateral parts of the petrosal apex such as the IAC and the jugular fossa, radical resection with acceptable neurological complications is mandatory because there is no alternative treatment achieving successful tumor control without risks of facial palsy or hearing deterioration. In contrast to numerous reports about transcranial approaches to these lateral petrosal areas, few reports have described the endoscopic endonasal approach, and a clear "inside" view of anatomy after anteromedial petrosectomy has not been previously demonstrated.

To clarify the technical feasibility and ideal application of the endoscopic transsphenoidal approach for petrous tumors, we present our experience with the endoscopic transsphenoidal anterior petrosal (ETAP) approach though the retrocarotid space. Anatomical landmarks to define the approach window and possible advantages of this approach compared with the open microscopic anterior petrosal approach are discussed.

\section{Methods \\ Patient Population}

Since 2010, we have performed endoscopic skull base surgery at our hospital in 54 patients harboring chordomas, 24 harboring meningiomas, and 18 harboring chondrosarcomas. In 10 of these patients, the tumors extensively extended to the lateral parts of the petrous apex, including the IAC and the jugular fossa, and we performed an ETAP approach. In one patient with recurrent chordomas, the tumors separately occupied the bilateral petrous regions. Thus, there were 11 tumors, comprising 7 chondrosarcomas, 3 chordomas, and 1 meningioma (Table 1). The indication for surgery was the need for radical resection of a tumor for which a surgical pathway using the transnasal transsphenoidal approach was expected to prove sufficient. Among these, 6 tumors were initially treated via the ETAP approach in our hospital, and the other 4 were referred to us after failure of various interventions, including transcra- nial surgeries ( 3 patients), endonasal surgeries ( 2 patients), and Gamma Knife radiosurgery (3 patients). The tumor showed invasion to the IAC in all 11 tumors, cavernous sinus in 10 , jugular fossa in 8 , clivus in 6 , and cerebellopontine angle (CPA) in 4.

Eight patients presented with diplopia (unilateral abducens nerve palsy), 3 with tinnitus, and 1 with unilateral hearing loss and facial palsy. In 1 patient, the tumor was markedly compressing the brainstem, and the patient presented with severe truncal ataxia with diplopia (Table 1).

\section{Surgical Procedure}

\section{Surgical Equipment}

Endoscopes, $4 \mathrm{~mm}$ in diameter with $0^{\circ}, 30^{\circ}$, and $70^{\circ}$ lenses, were used (rigid scopes, 175-180 mm long; Karl Storz Endoscopy Japan). In the nasal cavity and sphenoid sinus, surgical procedures were performed using a $0^{\circ}$ endoscope. After a sufficient surgical window was created in the retrocarotid space, $30^{\circ}$ and $70^{\circ}$ endoscopes were mainly used for confirmation of the anatomy around the petrous bone and tumor resection. A suction tube with irrigating function was useful to clear the endoscopic lens when it became clouded by mucus or blood. Narrow-shaft bipolar coagulators and various dissecting or curetting devices were used simultaneously. A high-frequency radiosurgical device with sharp malleable tip (Surgitron, Ellman International) was used to cut or remove the nasal mucosa. A drill system (Midas Rex, Medtronic Japan) with a diamond bur for the long and slightly curved shaft was used for removal of bony structures. To optimize the endoscopic approach to the lateral parts of the skull base regions, the tips of all instruments (ring curette, forceps, suction tip with irrigating function, and bipolar coagulators) were designed to be curved to various degrees with a long shaft or were malleable (Fujita Medical Instruments). Especially to dissect tumor components located lateral to the ICA from behind, the ring curettes with a shaft curved $90^{\circ}$ or $180^{\circ}$ in a semicircular shape were very useful. The endoscope was stabilized in the surgical field with a robotic holding device (Point Setter, Mitaka Kohki), and a neuronavigation system (StealthStation Navigation, Medtronic Japan) was routinely equipped.

The patient was placed supine with the head raised $15^{\circ}$. The head was fixed using a Mayfield 3-point headholder and slightly rotated toward the operator. Monitoring of cranial nerve function (electromyography of extraocular muscles, facial muscles, pharyngeal musculature with special tracheal tube, and tongue, and auditory brainstem response audiometry) was set to avoid cranial nerve injuries (Unique Medical).

\section{The ETAP Approach Through the Retrocarotid Space}

To swiftly deliver surgical tools without getting stuck in the nasal cavity while preserving the nasal anatomy, we used a low-profile nasal speculum specifically designed for endoscopic transnasal surgery (Fujita Medical Instruments) (Fig. 1A)..$^{30}$ The role of the nasal speculum in our surgery is to retract the redundant nasal tissues, such as the middle turbinates and nasal septum, during the surgery and prevent narrowing of the approach route by the 
TABLE 1. Characteristics of patients who underwent an ETAP approach for skull base tumors in the petrous bone

\begin{tabular}{|c|c|c|c|c|c|c|c|}
\hline $\begin{array}{l}\text { Case } \\
\text { No. }\end{array}$ & Pathology & $\begin{array}{l}\text { Age (yrs), } \\
\text { Sex }\end{array}$ & Side & Presentation & $\begin{array}{l}\text { Previous } \\
\text { Treatment }\end{array}$ & $\begin{array}{l}\text { Max Diameter/ } \\
\text { Vol }\left(\mathrm{cm} / \mathrm{cm}^{3}\right)\end{array}$ & Tumor Location \\
\hline 1 & Chordoma & $58, M$ & $\mathrm{Lt}$ & Diplopia (abducens palsy) & & $4.6 / 32.4$ & $\begin{array}{l}\text { Petrous bone (including IAC), cavernous } \\
\text { sinus, clivus, sphenoid sinus }\end{array}$ \\
\hline \multirow[t]{2}{*}{2} & Chordoma & $73, F$ & Rt & None & ES, RS & $3.8 / 11.6$ & $\begin{array}{l}\text { Petrous bone (including IAC), cavernous } \\
\text { sinus, occipital condyle }\end{array}$ \\
\hline & & & $\mathrm{Lt}$ & $\begin{array}{l}\text { Facial palsy, hearing loss, } \\
\text { tinnitus }\end{array}$ & RS & $4.5 / 24.5$ & $\begin{array}{l}\text { Petrous bone (including IAC), cavern- } \\
\text { ous sinus, jugular fossa, hypoglossal } \\
\text { canal, occipital condyle }\end{array}$ \\
\hline 3 & Chondrosarcoma & $32, \mathrm{M}$ & Rt & Diplopia (abducens palsy) & $\mathrm{Cr}$ & $4.1 / 16.7$ & $\begin{array}{l}\text { Petrous bone (including IAC), jugular } \\
\text { fossa, cavernous sinus, CPA, clivus, } \\
\text { middle cranial fossa }\end{array}$ \\
\hline 4 & Chondrosarcoma & $36, F$ & Rt & $\begin{array}{l}\text { Diplopia (abducens palsy), } \\
\text { tinnitus }\end{array}$ & & $4.2 / 21.1$ & $\begin{array}{l}\text { Petrous bone (including IAC), jugular } \\
\text { fossa, clivus hypoglossal canal, oc- } \\
\text { cipital condyle }\end{array}$ \\
\hline 5 & Chondrosarcoma & $36, \mathrm{M}$ & Rt & Diplopia (abducens palsy) & & $5.2 / 28.3$ & $\begin{array}{l}\text { Petrous bones (including IAC), jugular } \\
\text { fossa, bilateral cavernous sinuses, } \\
\text { CPA, clivus, sphenoid sinus }\end{array}$ \\
\hline 6 & Chondrosarcoma & $39, \mathrm{M}$ & $\mathrm{Lt}$ & $\begin{array}{l}\text { Diplopia (abducens palsy), } \\
\text { truncal ataxia }\end{array}$ & $\mathrm{Cr} \times 3$ & $6.7 / 88.4$ & $\begin{array}{l}\text { Petrous bone (including IAC), jugular } \\
\text { fossa, bilateral cavernous sinuses, } \\
\text { CPA, clivus, sphenoid sinus }\end{array}$ \\
\hline 7 & Chondrosarcoma & $48, M$ & $\mathrm{Lt}$ & $\begin{array}{l}\text { Diplopia (abducens palsy), } \\
\text { hypoglossal nerve palsy }\end{array}$ & & $4.6 / 14.5$ & $\begin{array}{l}\text { Petrous bone (including IAC), jugular } \\
\text { fossa, cavernous sinus, hypoglossal } \\
\text { canal, occipital condyle }\end{array}$ \\
\hline 8 & Chondrosarcoma & $49, F$ & Rt & Diplopia (abducens palsy) & & $3.7 / 11.8$ & $\begin{array}{l}\text { Petrous bone (including IAC), cavernous } \\
\text { sinus }\end{array}$ \\
\hline 9 & Chondrosarcoma & $77, \mathrm{~F}$ & $\mathrm{Lt}$ & Tinnitus & & $3.5 / 11.5$ & $\begin{array}{l}\text { Petrous bone (including IAC), jugular } \\
\text { fossa, cavernous sinus }\end{array}$ \\
\hline 10 & Meningioma & $54, \mathrm{~F}$ & $\mathrm{Lt}$ & Diplopia (abducens palsy) & Cr, ES, RS, RT & $6.0 / 64.6$ & $\begin{array}{l}\text { Petrous bone (including IAC), jugular } \\
\text { fossa, cavernous sinus, CPA, clivus, } \\
\text { sphenoid sinus }\end{array}$ \\
\hline
\end{tabular}

$\mathrm{Cr}=$ transcranial surgery; $\mathrm{ES}$ = endonasal surgery; $\mathrm{RS}$ = radiosurgery; $\mathrm{RT}$ = radiotherapy.

swollen nasal mucosa. For these purposes, we modified the conventional speculum blades to fit the endonasal transnasal approach, making them slimmer and much thinner than the ones used in microscopic transnasal surgery (Figs. 1A and 2A). With them, the flexibility of the nasal alae and apex are sufficiently preserved, and the approach pathway is not restricted at the entrance.

After making a linear incision on each side of the septal mucosa, we dissected the septal mucosa from the bony septum. Mucosal dissection was advanced to widely expose the anterior aspect of the sphenoid sinus, and each blade of the nasal speculum was inserted separately in each nostril. The opening width and angle of the blades can be modified in accordance with the individual shape of the nasal cavity, and the bony septum was temporarily displaced during surgery.

After wide anterior sphenoidotomy, the sellar floor, clival recess, carotid prominence, and bony prominence of the lateral wall compressed by the tumor were verified (Fig. 1B). When the vidian canal protrudes into the floor of the sphenoid sinus, which reaches the anterior genu of the ICA between the vertical and petrous segments, the route of the ICA is easily identified. ${ }^{25}$ The tumor was ap- proached through the retrocarotid triangular space, defined by the cavernous and vertical segments of the ICA, the clivus, and the petrooccipital fissure (Fig. 1C). Among these 3 anatomical limits, the lower part of the clival bone and posterior part of the petrooccipital cartilage are least likely to harbor the cranial nerves and ICA in the cases of petrous tumors. Drilling of the lateral bony prominence was started at the posterior part of the inferolateral corner in the sphenoid sinus (Fig. 1D). While the anteroposterior diameter of the approach window was determined based on the position of the ICA, the rostrocaudal diameter of the retrocarotid window was easily enlarged by drilling the petrous bone along the petrooccipital fissure (Fig. 1E), facilitating retention of a sufficient surgical pathway to the distal part of the petrous apex. After exposure of the tumor and ICA (Fig. 1F), dissection of the tumor from the surrounding anatomy was performed under direct visualization with the $30^{\circ}$ and $70^{\circ}$ endoscopes (Fig. 2A and B). On dissecting the tumor around the cranial nerves by the curettes or dissectors, surgical tools were carefully moved in the anteroposterior direction along their route in the cavernous sinus while carefully monitoring the electromyography of the extraocular muscles. 


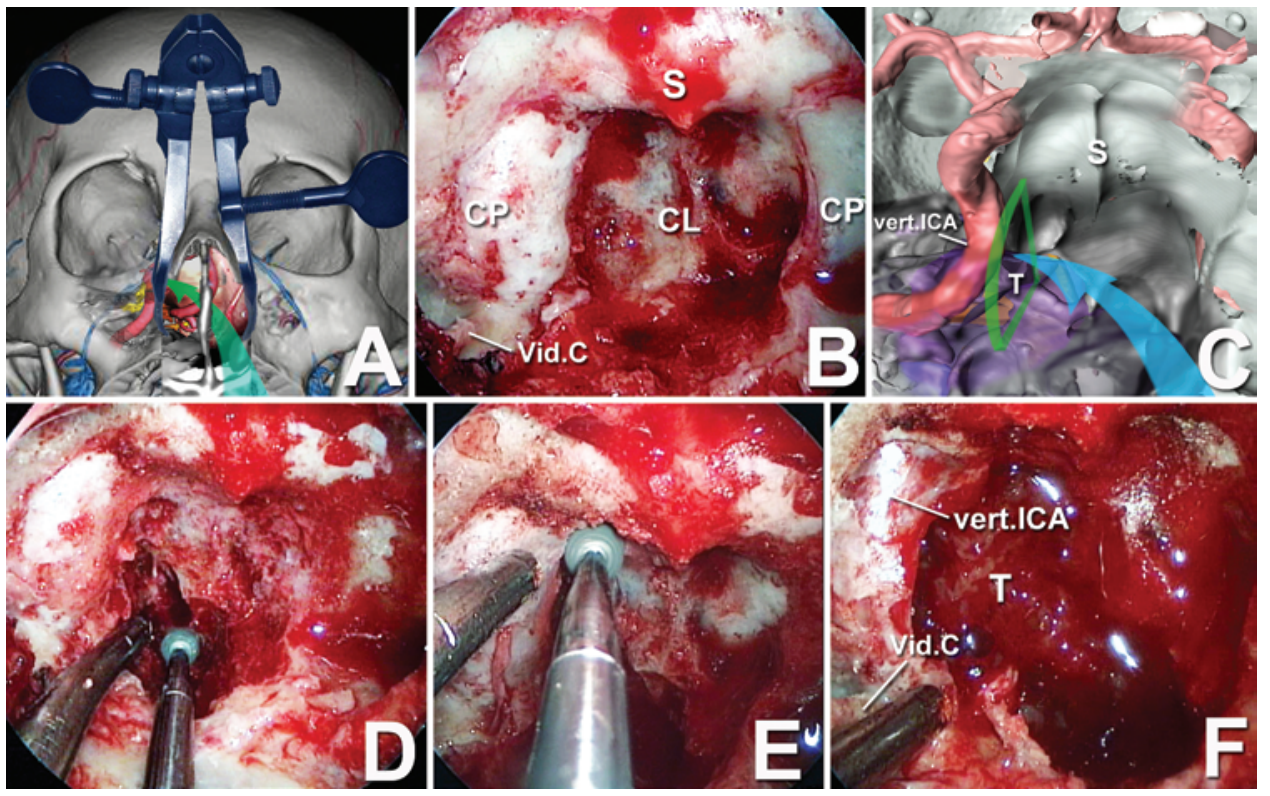

FIG. 1. A: Schematic of the surgical route (green arrow) for the ETAP approach using the low-profile adjustable nasal speculum. B: After a wide anterior sphenoidotomy, the sellar floor (S), clival recess (CL), vidian canal (Vid.C), and carotid prominence (CP) are verified. C: Schematic of the approach route in the sphenoid sinus (blue arrow). The route of the ICA is easily identified with the carotid prominences and vidian canal, and the tumor (T, purple area) is approached through the retrocarotid triangular space (area surrounded by green lines), defined by the vertical segments of the ICA (vert.ICA), the clivus, and the petrooccipital fissure. D and E: Drilling of the petrous bone is started at the posterior part of the inferolateral corner of the sphenoid sinus (D), and the retrocarotid window is enlarged in the rostrocaudal direction (E). F: The tumor (T) and vertical segment of the ICA (vert. ICA) are sufficiently exposed. Figure is available in color online only.

\section{Reconstruction of the Skull Base Defect}

After resection of the tumor, we carefully observed the cavity in the petrous bone (Fig. 2C). Fat tissues were harvested and fixed in the cavity of the petrous bone with fibrin glue to sufficiently cover the dura membrane along the IAC. When CSF leakage occurred from a small laceration of the petrous dura mater or thinned dura mater around the IAC, the tumor cavity was loosely packed with fat tissue and was mildly compressed by a sinus balloon inserted through the enlarged natural ostium of the sphenoid sinus. If the defect was relatively large and active CSF flow was observed continuously from the clival dural defect, the fascia lata was harvested, placed to cover the dural defect inside and outside the fistula and fixed with fibrin glue, and then compressed using a sinus balloon. In cases in which refractory CSF leakage was strongly anticipated, lumbar drainage with the aid of a CSF pressure valve (Acty Valve II, Kaneka Medical Products), a closed system allowing 1-way and pressure-controlled CSF flow, was also performed for 3 days. The nasal mucosa was nearly intact, with small bilateral incisions only on the septal mucosae and was preserved for the occasion of postoperative CSF rhinorrhea.

After reconstruction of the skull base floor, the nasal speculum was removed and the bony septum was placed between and glued to the bilateral septal mucosae using fibrin glue. Positions of the nasal turbinates were rectified, and absorbable gelatin film was placed outside the mid-

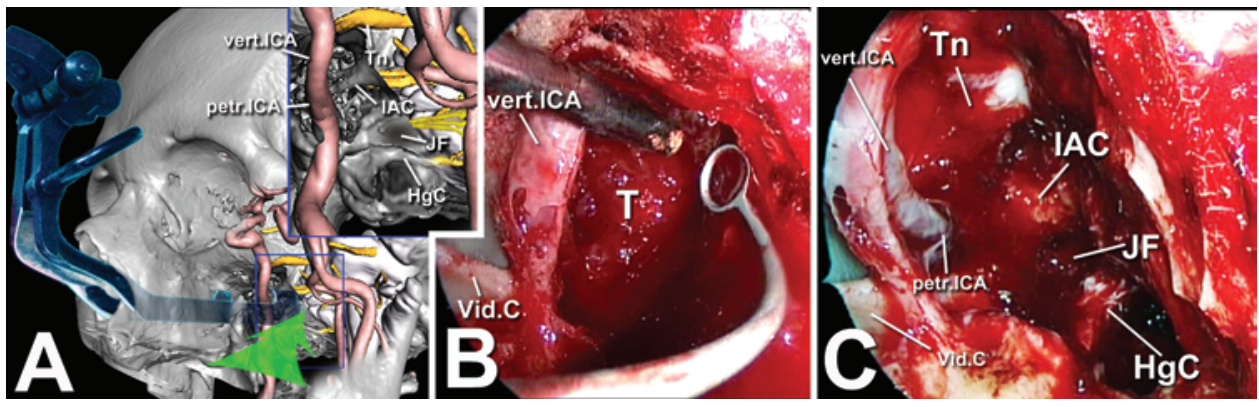

FIG. 2. A: Schematic of the surgical field observed through the retrocarotid window under the $30^{\circ}$ endoscope (green arrow). The blue-framed area on the schematic is magnified (inset), showing the routes of the trigeminal nerve (Tn), IAC, jugular fossa (JF), and hypoglossal canal $(\mathrm{HgC})$. B: Dissection of tumor $(\mathrm{T})$ from the surrounding anatomy is performed under direct visualization with the $30^{\circ}$ endoscope. Surgical tools are carefully moved in the anteroposterior direction (vertical segment of internal carotid artery, vert.ICA; vidian canal, Vid.C). C: After tumor resection, the cavity in the petrous bone is carefully observed. The trigeminal nerve (Tn), IAC, and jugular fossa (JF) are seen behind the ICA under the $70^{\circ}$ endoscope. Figure is available in color online only. 
dle turbinates (between the middle turbinate and lateral wall of the nasal cavity). Nasal packing with chitin-coated gauze was placed for 36 hours.

Each patient underwent endoscopic examination performed by an otolaryngologist at 1 week postoperatively. Patients visited our outpatient clinic at 1 month postoperatively for neurological evaluation and a second rhinological checkup.

\section{Results}

Representative cases are shown in Figs. 3-6. Of the 11 tumors, gross-total resection was achieved in 9 (Table 2). In 1 patient, postoperative MRI revealed residual enhancement on the margin of the occipital bone in contact with the jugular bulb, which was subsequently treated with radiosurgery (Case 5). In another patient with invasive meningioma, the tumor was strongly adherent to the ICA, requiring partial resection (Case 10, Fig. 6).

After surgery, all patients showed improvement in diplopia (Table 2). Among the 3 patients with tinnitus, 2 reported symptom resolution. In the patient presenting with unilateral hearing loss with facial palsy, the facial palsy completely resolved within 3 months, but hearing loss remained (Case 2, Fig. 3). In the patient presenting with severe truncal ataxia, symptoms improved markedly within 3 months (Case 6, Fig. 5).

Regarding complications, 3 patients showed mild and transient abducens nerve palsy (newly developed symptom in 1 patient resolving within 2 weeks, and aggravation of existing symptoms in 2 patients resolving within 3 months and 6 months). No patient exhibited hearing deterioration, facial palsy, or symptoms of lower cranial nerve palsy after surgery. Postoperative CSF rhinorrhea requiring surgical repair was observed in 1 patient (Case 4, Fig. 4); CSF leakage had not been apparent during surgery but suddenly occurred 1 week later. At surgical repair, no dural defect was evident, but continuous oozing of CSF was found around the internal auditory meatus. For this patient, abdominal fat was inserted into the petrous cavity, and a pedicled nasoseptal flap was used to ensure reconstruction.

\section{Discussion}

In this article, we present our experience with the ETAP approach for invasive skull base tumors involving the IAC, jugular fossa, and cavernous sinus. Our work may add new territories for the endoscopic transnasal approach for skull base tumors. In the literature, several authors have explored the potential application of the endonasal approach to various skull base regions in cadaveric studies. ${ }^{8,14,17,25}$ Recently, such laboratory work has contributed to extending accessible territories to the jugular tubercles and CPA. ${ }^{8,23}$ However, the endonasal approach to the lateral parts of the petrous apex, including the internal auditory meatus and jugular fossa, remains challenging. In healthy subjects, the ICA and cranial nerves constitute a lateral barrier to directly approaching these regions through the sphenoid sinus. In addition, the space remaining behind the vertical portion of the ICA is limited $d^{8,14,17,25}$ and seems to hamper the transsphenoidal approach to the petrosal

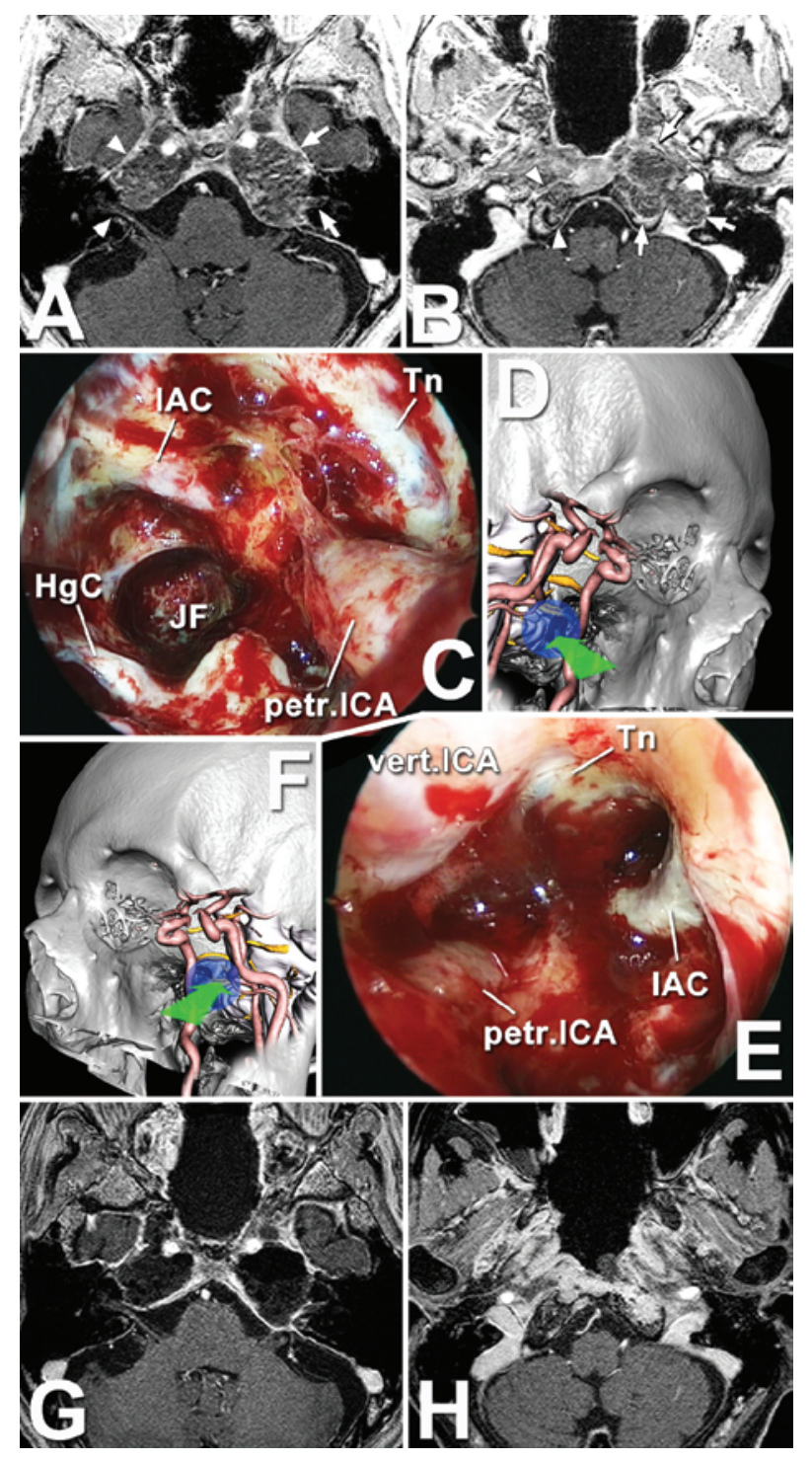

FIG. 3. Case 2. A case of chordoma invading into the bilateral petrous regions after failure of previous endonasal surgery and stereotactic radiosurgery. The patient presented with tinnitus, hearing loss, and left-sided facial palsy. A and B: Preoperative T1-weighted MR images with gadolinium enhancement (axial section at the level of the internal auditory meatus $[A]$ and axial section at the level of the jugular bulb $[B]$ ) revealing that the tumor completely involves the IAC and invades into the jugular bulb and occipital condyle (white arrows) on the left side (white arrowheads). On the right side, the tumor is invading the IAC and occipital condyle. C: After gross-total removal of the tumor in the left petrous bone, the routes of the trigeminal nerve $(\mathrm{Tn}), \mathrm{IAC}$, jugular foramen (JF), and hypoglossal canal $(\mathrm{HgC})$ are clearly disclosed with the petrous ICA (petr.ICA) under the $70^{\circ}$ endoscope. D: Schematic of the surgical field in the left petrous region (blue area), observed through the retrocarotid window under the $70^{\circ}$ endoscope (green arrow). E: After gross-total removal of the tumor in the right petrous bone, the routes of the trigeminal nerve $(\mathrm{Tn}), \mathrm{IAC}$, jugular foramen (JF), and vertical and petrous portions of the ICA (vert.ICA and petr.ICA, respectively) are observed under the $70^{\circ}$ endoscope. F: Schematic of the surgical field in the right petrous region (b/ue area), observed through the retrocarotid window under the $70^{\circ}$ endoscope (green arrow). G and H: Postoperative gadolinium-enhanced T1-weighted MR images (axial section at the level of the internal auditory meatus [G] and axial section at the level of the jugular bulb $[\mathrm{H}]$ ) showing total removal of the tumor bilaterally. Figure is available in color online only. 


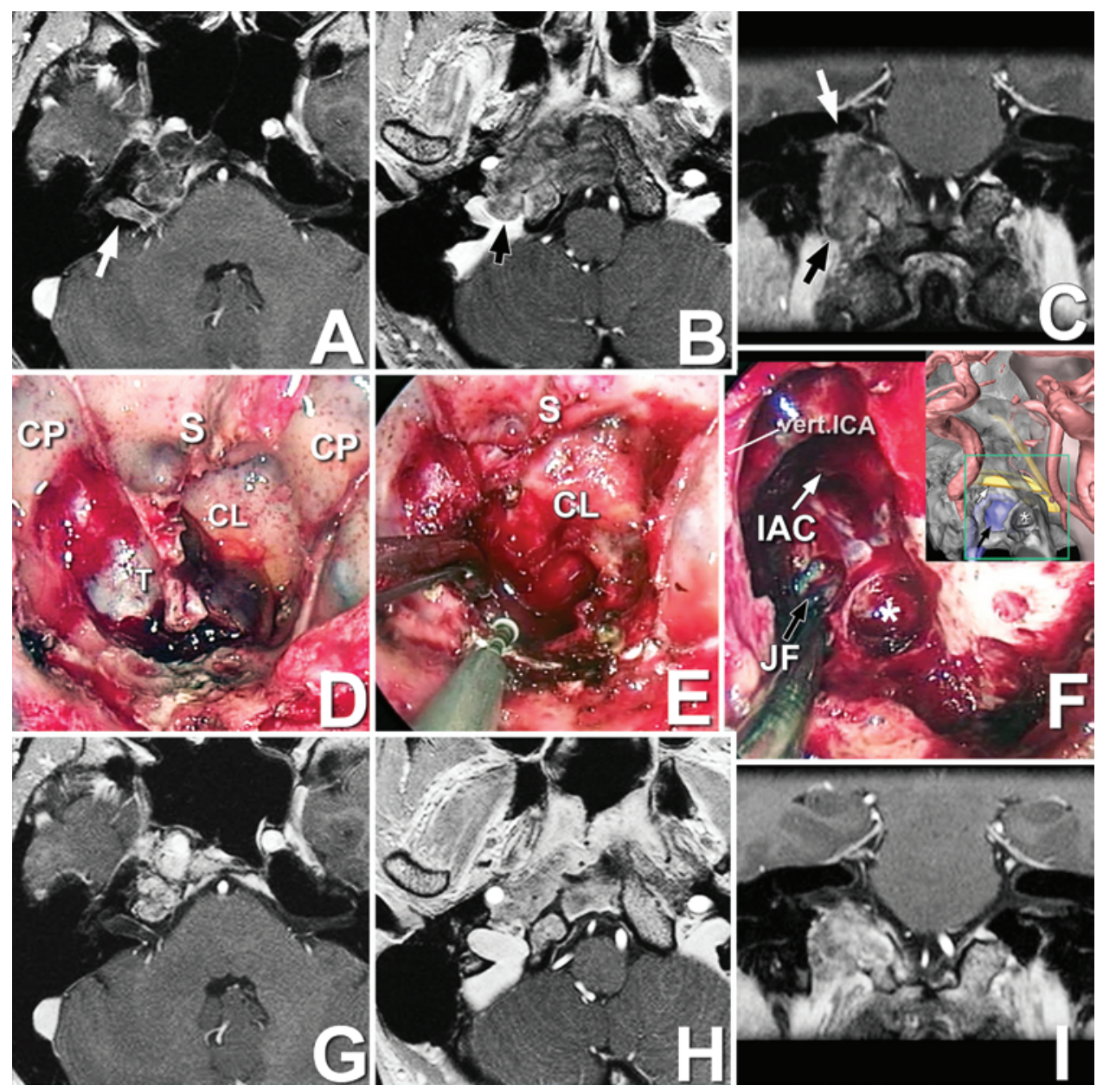

FIG. 4. Case 4. A case of chondrosarcoma extending into the right petrous region. A-C: Preoperative T1-weighted MR images with gadolinium enhancement (axial section at the level of the internal auditory meatus $[A]$, axial section at the level of the jugular bulb $[B]$, and coronal section [C]) revealing tumor invading into the IAC (white arrows in $A$ and $C$ ) and jugular bulb (black arrows in B and C). D: Intraoperatively, the anterior wall of the sphenoid sinus is widely opened, and the sella turcica (S), clival recess $(\mathrm{CL})$, and bilateral carotid prominences $(\mathrm{CP})$ are observed under the $0^{\circ}$ endoscope. The tumor $(\mathrm{T})$ is observed through the locally thinned clival bone. E: The petrous apex is drilled out in the retrocarotid space, exposing the soft but hemorrhagic tumor. F: After gross-total removal of the tumor, the IAC (white arrows), jugular foramen (JF, black arrows), and eroded condylar bone (white asterisks) are revealed under the $30^{\circ}$ endoscope. The inset illustrates the surgical field (green framed rectangle) with surrounding anatomical structures. G-I: Postoperative T1-weighted MR images with gadolinium enhancement (axial section at the level of the internal auditory meatus [G], axial section at the level of the jugular bulb [H], and coronal section [l]) disclose successful removal of the tumor and depicts abdominal fat packed in the cavity. Figure is available in color online only.

region. To the best of our knowledge, few clinical reports have described an endoscopic endonasal approach to skull base tumors involving the petrous apex or CPA..$^{23,24,32,41} \mathrm{In}$ these reports, a transsphenoidal approach from the retrocarotid window was undertaken only when the tumor was small and located close to the sphenoid sinus. ${ }^{32,41}$ Learning from cadaveric studies, the authors of those reports performed extensive removal of the normal nasal anatomy, including bilateral middle turbinectomies, wide septectomy, sphenoidotomy, and maxillotomy with removal of the pterygoid plate and pterygoid muscles. Skeletonization of the petrous carotid artery was performed to allow lateral mobilization to excise underlying tumor tissue and achieved successful resection of the tumors with acceptable levels of neurological complications. With those approaches, despite wide maintenance of straight surgical corridors, technical difficulties may impede extensive manipulation of the ICA. Simultaneously, in association with extensive resection of the nasal anatomy, the risk of postoperative nasal morbidity, including prolonged olfactory impairment, crusting, or discharge, should be anticipated. ${ }^{1-3,11} \mathrm{We}$ wonder if these sacrifices are inevitable and reasonable to expect in all patients undergoing the approach at this location.

Petrous apex lesions are often close to the clival recess and mobilize the ICA ventrally, thus creating sufficient corridors in the retrocarotid space. These corridors are not present in individuals who do not harbor these tumors. $12,23,24,32,41$ Learning from the clinical experience of transsphenoidal surgery for cystic inflammatory lesions in this region, we tried to approach skull base tumors occupying the petrous region and CPA through the retrocarotid triangle, demarcated by the cavernous and vertical segments of the ICA, the clival dura, and the petrooc- 

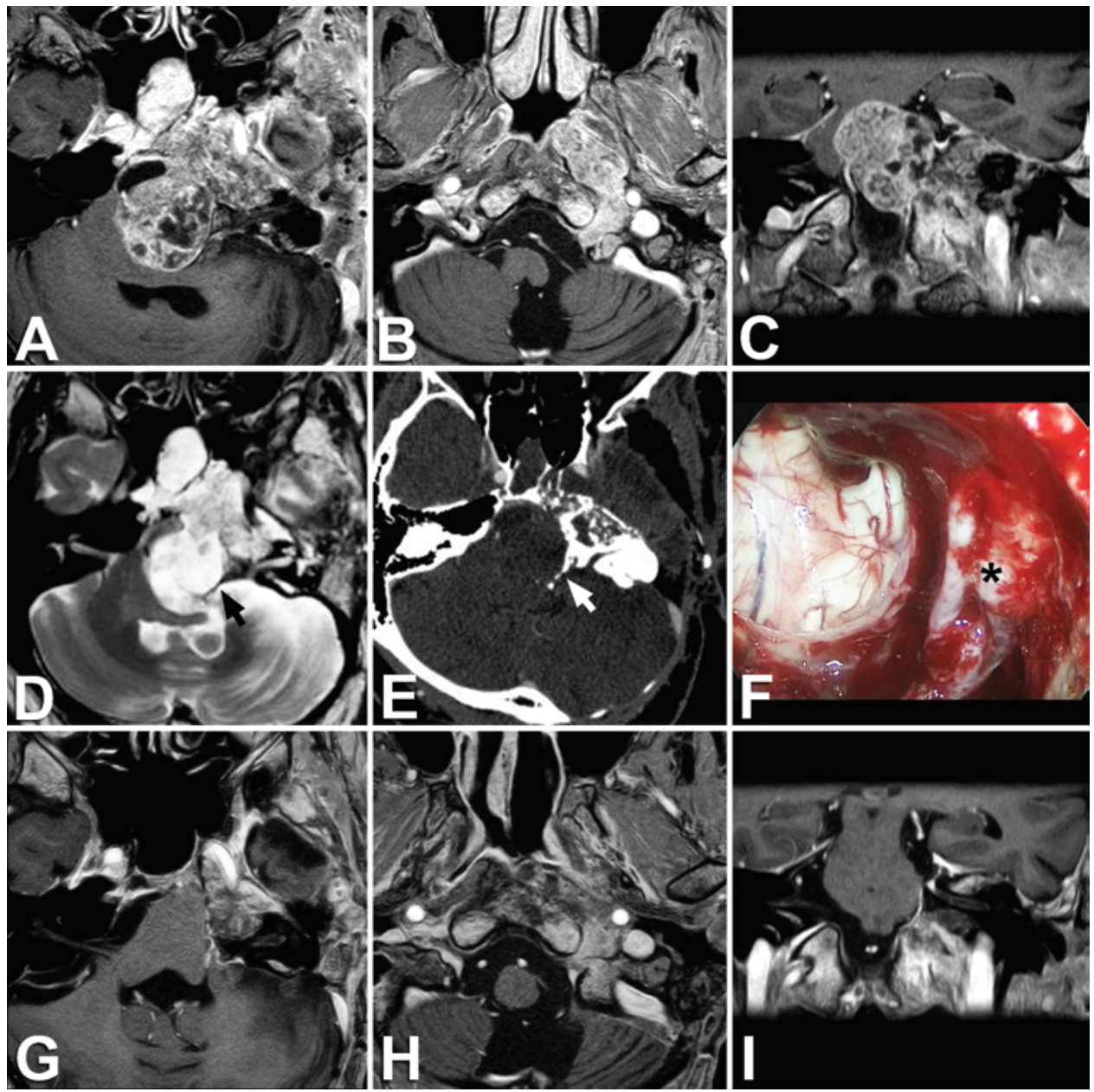

FIG. 5. Case 6. Chondrosarcoma in the left petrous region, extensively invading into the intracranial space. A-C: Preoperative T1-weighted MR images with gadolinium enhancement (axial section at the level of the internal auditory meatus [A], axial section at the level of the jugular bulb $[\mathrm{B}]$, and coronal section [C]) revealing the tumor markedly compressing the brainstem at the right CPA and invading into the right IAC, parapharyngeal space, and jugular foramen. D-F: On T2-weighted MRI (axial section at the level of the internal auditory meatus [D]), the tumor appeared highly intense in most of the parts, accompanied by the calcified rim stuck in the CPA, which appears as low intensity (black arrow) and high density on CT (E, white arrow). During surgery, the tumor was carefully dissected from the surface of the brainstem and the dura mater on the CPA (F, asterisk) and was removed with the calcified rim. G-I: Postoperative T1-weighted MR images with gadolinium enhancement (axial section at the level of the internal auditory meatus [G], axial section at the level of the jugular bulb [H], and coronal section [I]) showing successful tumor removal with release of brainstem compression. Figure is available in color online only.

cipital fissure (Fig. 1). While dissection and resection of the tumor mostly proceeded under the vision of angled endoscopes $\left(30^{\circ}\right.$ or $\left.70^{\circ}\right)$, the nasal speculum specially designed for endoscopic transsphenoidal surgery allowed stable maintenance of a wide surgical corridor with maximum preservation of the nasal anatomy, facilitating swift delivery of surgical tools and a clear, bloodless surgical field. ${ }^{30}$ To retain a sufficient surgical pathway, the retrocarotid window was enlarged along the petrooccipital fissure, minimizing the risk associated with skeletonization and mobilization of the ICA during the surgical procedure. Our results indicated that the transsphenoidal route was sufficient in a certain number of cases to approach the petrosal areas. Further expansion of the surgical field was not always necessary and should be considered in a stepwise fashion as appropriate during the surgery.

Compared with the transcranial anterior petrosal ap- proach, the ETAP approach may allow surgeons to reach more areas in the extradural regions around the petrous bone. In the transcranial approach, for tumors extending into the inferior portion of the petrous apex, such as the jugular fossa, the access is limited by the temporal lobe, the IAC, and the superior semicircular canal, which is better addressed by an endoscopic transnasal approach..$^{18,37}$ Also, it is easier to approach tumors that extensively involve the paramedian regions, such as the clivus, sphenoid sinus, and the nasopharyngeal region, or bilateral petrous apex, from the inside. ${ }^{10,28,30,35,39}$ In our cases, most of the tumors extended to the inferolateral part of the petrous apex or the paramedian regions and were considered suitable for the ETAP approach. However, experience with intradural lesions remains limited, and for intracranial tumors without skull base invasion, the transcranial approach remains warranted for safe surgical procedures at 

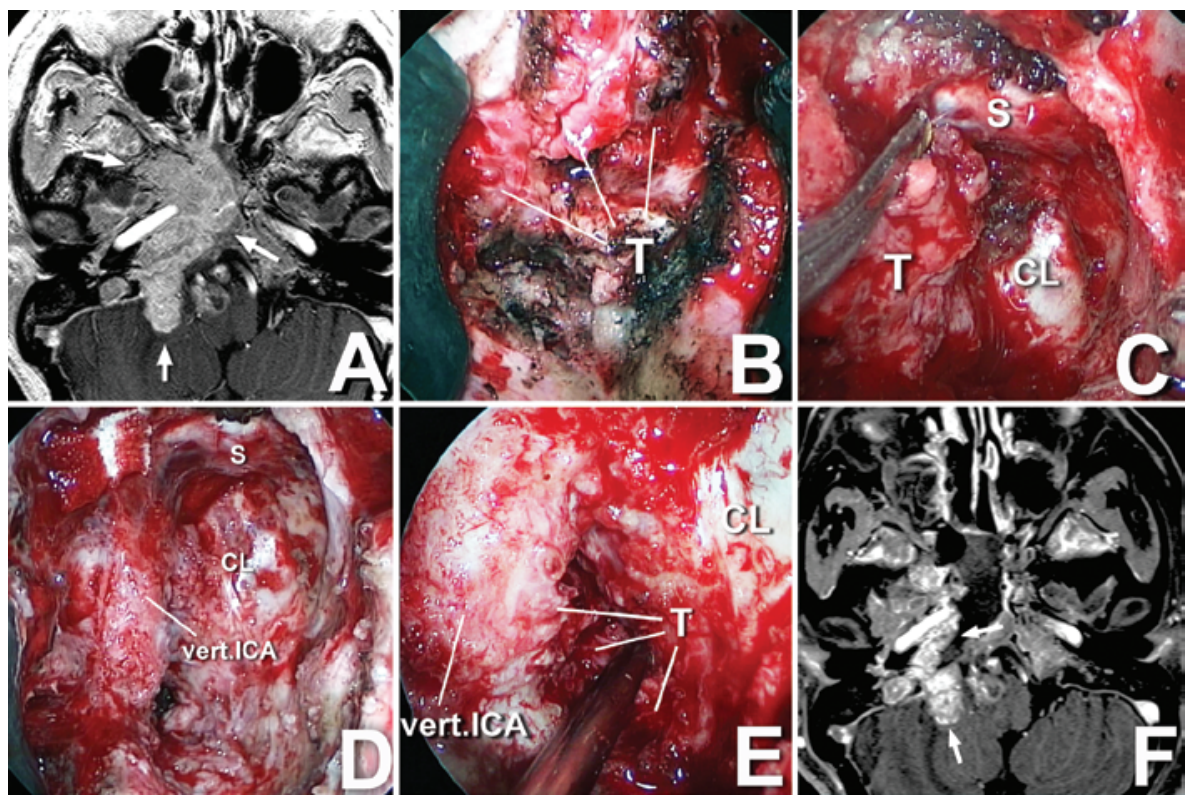

FIG. 6. Case 10. A case of recurrent invasive meningioma in the right petrous region. A: Preoperative T1-weighted MR image with gadolinium enhancement revealing recurrent tumor extensively invading into the petrous region, cavernous sinus, and right CPA (white arrows). B: After wide sphenoidotomy, the tumor ( $\mathrm{T}$ ) occupying the sphenoid sinus is exposed, appearing very fibrous, hard, and strongly adherent to surrounding structures. C: Under the $0^{\circ}$ endoscope, the tumor $(\mathrm{T})$ in the sphenoid sinus is carefully dissected from the sellar floor (S) and clivus (CL). D: The tumor is dissected from the ICA, and the anterior and medial aspects of the vertical portion of ICA (vert.ICA) are exposed. E: However, safe dissection of the tumor from the posterior aspect of the ICA with curved scissors is very difficult under the vision of the $30^{\circ}$ endoscope, resulting in partial resection. F: Postoperative T1-weighted MR image with gadolinium enhancement showing residual tumor in the petrous region behind the ICA, and the intracranial space (arrows). Figure is available in color online only.

TABLE 2. Surgical outcomes of the ETAP approach for skull base tumors in the petrous bone

\begin{tabular}{|c|c|c|c|c|c|c|}
\hline $\begin{array}{l}\text { Case } \\
\text { No. }\end{array}$ & Pathology & $\begin{array}{l}\text { Tumor Consistency/ } \\
\text { Adherence to Surroundings }\end{array}$ & $\begin{array}{l}\text { Extent of } \\
\text { Resection }\end{array}$ & Neurological Status After Surgery & $\begin{array}{l}\text { Adjuvant } \\
\text { Therapy }\end{array}$ & Follow-Up Status (mos) \\
\hline 1 & Chordoma & $\begin{array}{l}\text { Solid, partially soft/dissectible, } \\
\text { partially adherent }\end{array}$ & GTR & Diplopia resolved & & No recurrence (24) \\
\hline \multirow[t]{2}{*}{2} & Chordoma (rt) & Soft/easily dissectible & GTR & No deficit & & \multirow[t]{2}{*}{ No recurrence (24) } \\
\hline & Chordoma (It) & Soft/easily dissectible & GTR & $\begin{array}{l}\text { Facial palsy resolved; hearing loss } \\
\text { remained }\end{array}$ & & \\
\hline 3 & Chondrosarcoma & Soft/easily dissectible & GTR & Diplopia resolved & & No recurrence (18) \\
\hline 4 & Chondrosarcoma & Soft/easily dissectible & GTR & Diplopia resolved \& tinnitus improved & & $\begin{array}{l}\text { CSF rhinorrhea surgi- } \\
\text { cally repaired; no } \\
\text { recurrence }(48)\end{array}$ \\
\hline 5 & Chondrosarcoma & $\begin{array}{l}\text { Solid, partially fibrous/dis- } \\
\text { sectible, partially adherent }\end{array}$ & STR & Diplopia resolved & $\mathrm{RS}$ & No recurrence $(30)$ \\
\hline 6 & Chondrosarcoma & $\begin{array}{l}\text { Solid/dissectible, partially } \\
\text { adherent }\end{array}$ & GTR & $\begin{array}{l}\text { Transient worsening of abductor palsy for } \\
6 \text { mos; diplopia \& truncal ataxia finally } \\
\text { resolved }\end{array}$ & & No recurrence (25) \\
\hline 7 & Chondrosarcoma & $\begin{array}{l}\text { Solid, partially fibrous/dis- } \\
\text { sectible, partially adherent }\end{array}$ & GTR & $\begin{array}{l}\text { Diplopia resolved; no change in hypo- } \\
\text { glossal nerve palsy }\end{array}$ & & No recurrence (23) \\
\hline 8 & Chondrosarcoma & $\begin{array}{l}\text { Soft, partially solid/dissectible, } \\
\text { partially adherent }\end{array}$ & GTR & $\begin{array}{l}\text { Transient worsening of abductor palsy, } \\
\text { which continued for } 3 \text { mos; diplopia } \\
\text { finally resolved }\end{array}$ & & No recurrence (21) \\
\hline 9 & Chondrosarcoma & Soft, partially solid/dissectible & GTR & $\begin{array}{l}\text { Transient abducent nerve palsy, resolved } \\
\text { in } 2 \text { wks; tinnitus improved }\end{array}$ & & No recurrence (33) \\
\hline 10 & Meningioma & Fibrous/strongly adherent & PR & Diplopia improved & RT & $\begin{array}{l}\text { Growth of residual } \\
\text { tumor evident after } 6 \\
\text { mos (20) }\end{array}$ \\
\hline
\end{tabular}

GTR = gross-total resection; PR = partial resection; STR = subtotal resection. 
present. ${ }^{18,29,40}$ Our results suggested that, in the ETAP approach, the extent of tumor resection largely depends on tumor characteristics. For relatively soft tumors, we can remove the petrous lesions regardless of the size of the retrocarotid space and reach the lateral part of the petrous apex. For partially calcified and relatively solid tumors, meticulous microsurgical techniques often allow dissection from surrounding structures. Thus, if we can maintain a sufficient surgical window in the retrocarotid space, the tumor can be successfully removed (Fig. 5). On the other hand, if the tumor is fibrous and adherent to the ICA or involves cranial nerves in the cavernous sinus, dissection from the surrounding critical anatomy and safe removal of the tumor will likely prove difficult (Fig. 6). Accurately predicting tumor consistency and dissectability from surrounding anatomy based on preoperative radiographic images is problematic. ${ }^{7,13,26,27,33}$ For fibrous tumors involving critical anatomical structures, application of the ETAP approach should be carefully discussed in each case, taking into consideration the histological diagnosis, preoperative neurological findings, and the possibility of other surgical approaches or treatment modalities.

\section{Conclusions}

The ETAP approach offers a simple, less invasive alternative for invasive skull base tumors involving the petrous region, including the IAC, jugular fossa, and cavernous sinus. Since a larger number of patients is needed to clarify the efficacy and safety of an approach, the applicability of the ETAP approach should be carefully determined for the individual patient, considering the size of the retrocarotid window and tumor characteristics.

\section{References}

1. Alobid I, Enseñat J, Mariño-Sánchez F, de Notaris M, Centellas S, Mullol J, et al: Impairment of olfaction and mucociliary clearance after expanded endonasal approach using vascularized septal flap reconstruction for skull base tumors. Neurosurgery 72:540-546, 2013

2. Alobid I, Enseñat J, Mariño-Sánchez F, Rioja E, de Notaris M, Mullol J, et al: Expanded endonasal approach using vascularized septal flap reconstruction for skull base tumors has a negative impact on sinonasal symptoms and quality of life. Am J Rhinol Allergy 27:426-431, 2013

3. Bedrosian JC, McCoul ED, Raithatha R, Akselrod OA, Anand VK, Schwartz TH: A prospective study of postoperative symptoms in sinonasal quality-of-life following endoscopic skull-base surgery: dissociations based on specific symptoms. Int Forum Allergy Rhinol 3:664-669, 2013

4. Cavallo LM, Solari D, Esposito F, Villa A, Minniti G, Cappabianca $P$ : The role of the endoscopic endonasal route in the management of craniopharyngiomas. World Neurosurg 82 (6 Suppl):S32-S40, 2014

5. Chabot JD, Gardner P, Fernandez-Miranda JC: Anterior transpetrosal approach for resection of recurrent skull base chordoma: 3-dimensional operative video. Neurosurgery 11 (Suppl 3):464-465, 2015

6. Conger AR, Lucas J, Zada G, Schwartz TH, Cohen-Gadol AA: Endoscopic extended transsphenoidal resection of craniopharyngiomas: nuances of neurosurgical technique. Neurosurg Focus 37(4):E10, 2014

7. Copeland WR, Hoover JM, Morris JM, Driscoll CL, Link MJ: Use of preoperative MRI to predict vestibular schwan- noma intraoperative consistency and facial nerve outcome. J Neurol Surg B Skull Base 74:347-350, 2013

8. Fernandez-Miranda JC, Morera VA, Snyderman CH, Gardner P: Endoscopic endonasal transclival approach to the jugular tubercle. Neurosurgery 71 (1 Suppl Operative):146-159, 2012

9. Fortes FS, Sennes LU, Carrau RL, Brito R, Ribas GC, Yasuda A, et al: Endoscopic anatomy of the pterygopalatine fossa and the transpterygoid approach: development of a surgical instruction model. Laryngoscope 118:44-49, 2008

10. Fraser JF, Nyquist GG, Moore N, Anand VK, Schwartz TH: Endoscopic endonasal transclival resection of chordomas: operative technique, clinical outcome, and review of the literature. J Neurosurg 112:1061-1069, 2010

11. Georgalas C, Badloe R, van Furth W, Reinartz S, Fokkens WJ: Quality of life in extended endonasal approaches for skull base tumours. Rhinology 50:255-261, 2012

12. Hofstetter CP, Singh A, Anand VK, Kacker A, Schwartz TH: The endoscopic, endonasal, transmaxillary transpterygoid approach to the pterygopalatine fossa, infratemporal fossa, petrous apex, and the Meckel cave. J Neurosurg 113:967-974, 2010

13. Ishikawa M, Nishi S, Aoki T, Takase T, Wada E, Oowaki H, et al: Predictability of internal carotid artery (ICA) dissectability in cases showing ICA involvement in parasellar meningioma. J Clin Neurosci 8 (Suppl 1):22-25, 2001

14. Jacquesson T, Simon E, Berhouma M, Jouanneau E: Anatomic comparison of anterior petrosectomy versus the expanded endoscopic endonasal approach: interest in petroclival tumors surgery. Surg Radiol Anat 37:1199-1207, 2015

15. Jho HD, Carrau RL: Endoscopic endonasal transsphenoidal surgery: experience with 50 patients. J Neurosurg 87:44-51, 1997

16. Jho HD, Carrau RL, Ko Y, Daly MA: Endoscopic pituitary surgery: an early experience. Surg Neurol 47:213-223, 1997

17. Kasemsiri P, Solares CA, Carrau RL, Prosser JD, Prevedello DM, Otto BA, et al: Endoscopic endonasal transpterygoid approaches: anatomical landmarks for planning the surgical corridor. Laryngoscope 123:811-815, 2013

18. Kawase T, Shiobara R, Toya S: Anterior transpetrosaltranstentorial approach for sphenopetroclival meningiomas: surgical method and results in 10 patients. Neurosurgery 28:869-876, 1991

19. Khan OH, Krischek B, Holliman D, Klironomos G, Kucharczyk W, Vescan A, et al: Pure endoscopic expanded endonasal approach for olfactory groove and tuberculum sellae meningiomas. J Clin Neurosci 21:927-933, 2014

20. Koutourousiou M, Fernandez-Miranda JC, Wang EW, Snyderman $\mathrm{CH}$, Gardner PA: Endoscopic endonasal surgery for olfactory groove meningiomas: outcomes and limitations in 50 patients. Neurosurg Focus 37(4):E8, 2014

21. Mason E, Gurrola J II, Reyes C, Brown JJ, Figueroa R, Solares CA: Analysis of the petrous portion of the internal carotid artery: landmarks for an endoscopic endonasal approach. Laryngoscope 124:1988-1994, 2014

22. McLaughlin N, Kelly DF, Prevedello DM, Shahlaie K, Carrau RL, Kassam AB: Endoscopic endonasal management of recurrent petrous apex cholesterol granuloma. J Neurol Surg B Skull Base 73:190-196, 2012

23. Mesquita Filho PM, Ditzel Filho LF, Prevedello DM, Martinez CA, Fiore ME, Dolci RL, et al: Endoscopic endonasal surgical management of chondrosarcomas with cerebellopontine angle extension. Neurosurg Focus 37(4):E13, 2014

24. Moussazadeh N, Kulwin C, Anand VK, Ting JY, Gamss C, Iorgulescu JB, et al: Endoscopic endonasal resection of skull base chondrosarcomas: technique and early results. J Neurosurg 122:735-742, 2015

25. Osawa S, Rhoton AL Jr, Seker A, Shimizu S, Fujii K, Kassam AB: Microsurgical and endoscopic anatomy of the vidian canal. Neurosurgery 64 (5 Suppl 2):385-412, 2009 
26. Pierallini A, Caramia F, Falcone C, Tinelli E, Paonessa A, Ciddio AB, et al: Pituitary macroadenomas: preoperative evaluation of consistency with diffusion-weighted MR imaging-initial experience. Radiology 239:223-231, 2006

27. Romani R, Tang WJ, Mao Y, Wang DJ, Tang HL, Zhu FP, et al: Diffusion tensor magnetic resonance imaging for predicting the consistency of intracranial meningiomas. Acta Neurochir (Wien) 156:1837-1845, 2014

28. Saito K, Toda M, Tomita T, Ogawa K, Yoshida K: Surgical results of an endoscopic endonasal approach for clival chordomas. Acta Neurochir (Wien) 154:879-886, 2012

29. Saito N, Sasaki T, Chikui E, Yuyama R, Kirino T: Anterior transpetrosal approach for pontine cavernous angioma-case report. Neurol Med Chir (Tokyo) 42:272-274, 2002

30. Shin M, Kondo K, Kin T, Suzukawa K, Saito N: Endoscopic transnasal interseptal approach for invasive clival tumors: development of an approach method regarding maximal preservation of the nasal anatomy. Neurol Med Chir (Tokyo) 55:336-344, 2015

31. Shin M, Kondo K, Saito N: Neuroendoscopic transnasal surgery for skull base tumors: basic approaches, avoidance of pitfalls, and recent innovations. Neurol Med Chir (Tokyo) 52:697-703, 2012

32. Simal-Julián JA, Miranda-Lloret P, Botella-Asunción C, Kassam A: Full endoscopic endonasal expanded approach to the petroclival region: optimizing the carotid-clival window. Acta Neurochir (Wien) 156:1627-1629, 2014 [Erratum in Acta Neurochir (Wien) 156:1927, 2014]

33. Sitthinamsuwan B, Khampalikit I, Nunta-aree S, Srirabheebhat P, Witthiwej T, Nitising A: Predictors of meningioma consistency: A study in 243 consecutive cases. Acta Neurochir (Wien) 154:1383-1389, 2012

34. Steiger HJ, Hänggi D, Stummer W, Winkler PA: Customtailored transdural anterior transpetrosal approach to ventral pons and retroclival regions. J Neurosurg 104:38-46, 2006

35. Stippler M, Gardner PA, Snyderman CH, Carrau RL, Prevedello DM, Kassam AB: Endoscopic endonasal approach for clival chordomas. Neurosurgery 64:268-278, 2009

36. Terranova P, Karligkiotis A, Gallo S, Meloni F, Bignami M, Castelnuovo P: A novel endoscopic technique for long-term patency of cholesterol granulomas of the petrous apex. Laryngoscope 123:2639-2642, 2013
37. Van Gompel JJ, Alikhani P, Tabor MH, van Loveren HR, Agazzi S, Froelich S, et al: Anterior inferior petrosectomy: defining the role of endonasal endoscopic techniques for petrous apex approaches. J Neurosurg 120:1321-1325, 2014

38. Yano S, Hide T, Shinojima N, Hasegawa Y, Kawano T, Kuratsu J: Endoscopic endonasal skull base approach for parasellar lesions: Initial experiences, results, efficacy, and complications. Surg Neurol Int 5:51, 2014

39. Yen YS, Chang PY, Huang WC, Wu JC, Liang ML, Tu TH, et al: Endoscopic transnasal odontoidectomy without resection of nasal turbinates: clinical outcomes of 13 patients. J Neurosurg Spine 21:929-937, 2014

40. Yoshida K, Kawase T: Trigeminal neurinomas extending into multiple fossae: surgical methods and review of the literature. J Neurosurg 91:202-211, 1999

41. Zanation AM, Snyderman CH, Carrau RL, Gardner PA, Prevedello DM, Kassam AB: Endoscopic endonasal surgery for petrous apex lesions. Laryngoscope 119:19-25, 2009

\section{Disclosures}

The authors report no conflict of interest concerning the materials or methods used in this study or the findings specified in this paper.

\section{Author Contributions}

Conception and design: Shin, Kondo, Saito. Acquisition of data: Shin, Hanakita, Hasegawa, Yoshino, Teranishi. Analysis and interpretation of data: Shin, Kondo, Hanakita, Hasegawa, Yoshino, Teranishi. Drafting the article: Shin, Kondo, Kin. Critically revising the article: Kondo, Hanakita, Hasegawa, Saito. Reviewed submitted version of manuscript: all authors. Approved the final version of the manuscript on behalf of all authors: Shin. Administrative/technical/material support: Kin. Study supervision: Saito.

\section{Correspondence}

Masahiro Shin, Department of Neurosurgery, The University of Tokyo Hospital, 7-3-1, Hongo, Bunkyo-ku, Tokyo 133-8655, Japan.email: shin-nsu@h.u-tokyo.ac.jp. 